Pacific Journal of Mathematics

SUPER-REFLEXIVE SPACES WITH BASES 


\section{SUPER-REFLEXIVE SPACES WITH BASES}

\section{ROBERT C. JAMES}

Super-reflexivity is defined in such a way that all superreflexive Banach spaces are reflexive and a Banach space is super-reflexive if it is isomorphic to a Banach space that is either uniformly convex or uniformly non-square. It is shown that, if $0<2 \phi<\varepsilon \leqq 1<\Phi$ and $B$ is super-reflexive, then there are numbers $r$ and $s$ for which $1<r<\infty$, $1<s<\infty$ and, if $\left\{e_{i}\right\}$ is any normalized basic sequence in $B$ with characteristic not less than $\varepsilon$, then

$$
\phi\left[\Sigma\left|a_{i}\right|^{r}\right]^{1 / r} \leqq\left\|\Sigma a_{i} e_{i}\right\| \leqq \Phi\left[\Sigma\left|a_{i}\right|^{s}\right]^{1 / s},
$$

for all numbers $\left\{a_{i}\right\}$ such that $\Sigma a_{i} e_{i}$ is convergent. This also is true for unconditional basic subsets in nonseparable super-reflexive Banach spaces. Gurariř and Gurariǐ recently established the existence of $\phi$ and $r$ for uniformly smooth spaces, and the existence of $\Phi$ and $s$ for uniformly convex spaces [Izv. Akad. Nauk SSSR Ser. Mat., 35 (1971), 210-215].

A basis for a Banach space $B$ is a sequence $\left\{e_{i}\right\}$ such that, for each $x$ in $B$, there is a unique sequence of numbers $\left\{a_{i}\right\}$ such that $\sum_{1}^{\infty} a_{i} e_{i}$ converges strongly to $x$, i.e.,

$$
\lim _{n \rightarrow \infty}\left\|x-\sum_{1}^{n} a_{i} e_{i}\right\|=0 \text {. }
$$

A normalized basis is a basis $\left\{e_{i}\right\}$ such that $\left\|e_{i}\right\|=1$ for all $i$.

A basic sequence is any sequence that is a basis for its closed linear span.

It apparently was known to Banach (see [1, pg. 111] and [3]) that a sequence $\left\{e_{i}\right\}$ whose linear span is dense in a Banach space $B$ is a basis for $B$ if and only if there is a number $\varepsilon>0$ such that

$$
\left\|\sum_{1}^{n} a_{i} e_{i}\right\| \geqq \varepsilon\left\|\sum_{1}^{k} a_{i} e_{i}\right\|
$$

if $k<n$ and $\left\{a_{i}\right\}$ is any sequence of numbers. The largest such number $\varepsilon$ is the characteristic of the basis. It follows directly from the triangle inequality that, if $1 \leqq p \leqq q \leqq n$, then

$$
\left\|\sum_{1}^{n} a_{i} e_{i}\right\| \geqq \frac{1}{2} \varepsilon\left\|\sum_{p}^{q} a_{i} e_{i}\right\| \text {. }
$$

An unconditional basis for a Banach space $B$ is a subset $\left\{e_{\alpha}\right\}$ of $B$ such that for each $x$ in $B$ there is a unique sequence of ordered 
pairs $\left(a_{i}, e_{\alpha(i)}\right)$ such that $\sum_{1}^{\infty} a_{i} e_{\alpha(i)}$ converges strongly and unconditionally to $x$. By arguments similar to those used in [1] and [3] for a basis, it can be shown that a subset $\left\{e_{\alpha}\right\}$ whose linear span is dense in $B$ is an unconditional basis for $B$ if and only if there is a characteristic $\varepsilon$ for which

$$
\left\|\sum_{A} a_{\alpha} e_{\alpha}\right\| \geqq \varepsilon\left\|\sum_{B} a_{\alpha} e_{\alpha}\right\|,
$$

if $B \subset A$ and $A$ is a finite subset of the index set.

A uniformly non-square Banach space is a Banach space $B$ for which there is a positive number $\delta$ such that there do not exist members $x$ and $y$ of $B$ for which $\|x\| \leqq 1,\|y\| \leqq 1$,

$$
\left\|\frac{1}{2}(x+y)\right\|>1-\delta \text { and }\left\|\frac{1}{2}(x-y)\right\|>1-\delta .
$$

A uniformly convex space is uniformly non-square and a uniformly non-square space is reflexive [6, Theorem 1.1].

THEOREM 1. The following properties are equivalent for normed linear spaces $X$, each of them is implied by nonreflexivity of the completion of $X$, and each is self-dual. If a normed linear space $X$ has any one of these properties, then $X$ is not isomorphic to any space that is uniformly non-square.

(i) There exists a positive number $\theta$ such that, for every positive integer $n$, there are subsets $\left\{z_{1}, \cdots, z_{n}\right\}$ and $\left\{g_{1}, \cdots, g_{n}\right\}$ of the unit balls of $X$ and $X^{*}$, respectively, such that

$$
g_{i}\left(z_{j}\right)=\theta \quad \text { if } \quad i \leqq j, g_{i}\left(z_{j}\right)=0 \quad \text { if } \quad i>j .
$$

(ii) There exist positive numbers $\alpha$ and $\beta$ such that, for every positive integer $n$, there is a subset $\left\{x_{1}, \cdots, x_{n}\right\}$ of the unit ball of $X$ for which $\|x\|>\alpha$ if $x \in \operatorname{conv}\left\{x_{1}, \cdots, x_{n}\right\}$ and, for every positive integer $k<n$ and all numbers $\left\{a_{1}, \cdots, a_{n}\right\}$,

$$
\left\|\sum_{1}^{n} a_{i} x_{i}\right\| \geqq \beta\left\|\sum_{1}^{k} a_{i} x_{i}\right\| \text {. }
$$

(iii) There exist positive numbers $\alpha^{\prime}$ and $\beta^{\prime}$ such that, for every positive integer $n$, there is a subset $\left\{x_{1}, \cdots, x_{n}\right\}$ of $X$ which has the property that, for every positive integer $k<n$ and all numbers $\left\{a_{i}\right\}$,

$$
\left\|\sum_{1}^{n} a_{i} x_{i}\right\| \geqq \alpha^{\prime} \sup \left|a_{i}\right| \text { and }\left\|\sum_{1}^{k} x_{i}\right\|<\beta^{\prime} .
$$

Proof. It is known that Theorem 1 is valid for properties (i) and (ii) [8, Theorem 6]. We shall show that (i) and (iii) are equivalent. 
If (i) is satisfied, let $x_{1}=z_{1}$ and $x_{i}=z_{i}-z_{i-1}$ if $1<i \leqq n$. Then $g_{i}\left(x_{j}\right)=\delta_{i}^{j} \theta$, so that

$$
\left\|\sum_{1}^{n} a_{i} x_{i}\right\| \geqq\left|g_{k}\left(\sum_{1}^{n} a_{i} x_{i}\right)\right|=\theta\left|a_{k}\right|,
$$

and $\left\|\sum_{1}^{k} x_{i}\right\|=\left\|z_{k}\right\| \leqq 1$. Thus (iii) is satisfied.

If (iii) is satisfied, let $z_{k}=\sum_{1}^{k} x_{i} / \beta^{\prime}$. Define $g_{j}$ on $\operatorname{lin}\left\{z_{1}, \cdots, z_{n}\right\}$ by letting $g_{i}\left(x_{j}\right)=\delta_{i}^{j} \alpha^{\prime}$. Then $\left\|z_{k}\right\|<1$ and

$$
\left|g_{j}\left(\sum_{1}^{n} a_{i} x_{i}\right)\right|=\alpha^{\prime}\left|a_{j}\right| \leqq\left\|\sum_{1}^{n} a_{i} x_{i}\right\|,
$$

so that $g_{j}$ can be extended to all of the space with $\left\|g_{j}\right\| \leqq 1$. Also, $g_{i}\left(z_{j}\right)=\alpha^{\prime} / \beta^{\prime}$ if $i \leqq j$ and $g_{i}\left(z_{j}\right)=0$ if $i>j$, so that ( $\mathrm{i}$ ) is satisfied.

Definition. A super-reflexive Banach space is a Banach space that does not have any of the equivalent properties (i), (ii) and (iii) described in the statement of Theorem 1.

This is a natural definition, since a Banach space is non-reflexive if and only if (i) of Theorem 1 is satisfied by infinite sequences $\left\{z_{i}\right\}$ and $\left\{g_{i}\right\}$. Moreover, there are several other finitely stated properties that are equivalent to (i), but which become equivalent to nonreflexivity when stated for infinite sequences [8, Theorem 3].

THEOREM 2. Let $B$ be a super-reflexive Banach space. If $\Phi>1$ and $0<\varepsilon \leqq 1$, then there is a number $s$ for which $1<s<\infty$ and, if $\left\{e_{i}\right\}$ is any normalized basic sequence in $B$ with characteristic not less than $\varepsilon$, then

$$
\left\|\sum a_{i} e_{i}\right\| \leqq \Phi\left[\sum\left|a_{i}\right|^{s}\right]^{1 / s}
$$

for all numbers $\left\{a_{i}\right\}$ such that $\sum a_{i} e_{i}$ is convergent.

Proof. It will be shown that, if there are numbers $\Phi$ and $\varepsilon$ for which $\Phi>1,0<\varepsilon \leqq 1$, and there does not exist such a number $s$, then $B$ has property (ii) of Theorem 1 with $\alpha=1 / 2$ and $\beta=\varepsilon$. Let $n$ be an arbitrary positive integer greater than 1 . Let $\theta$ be a number for which

$$
1-\frac{1}{2 n}<\theta<1
$$

Then choose $\lambda$ such that $\theta^{1 / 4}<\lambda<1, \lambda^{2} \Phi>1$, and

$$
\frac{(\Phi+1)\left(1-\lambda^{2}\right)}{\lambda^{2} \Phi-1}<\frac{1}{n}\left(1-\theta^{1 / 4}\right) .
$$

Choose $s>1$ and close enough to 1 that $\lambda n<n^{1 / s}$. Then 


$$
\begin{aligned}
& (\alpha+\beta)^{1 / s} \geqq \lambda\left(\alpha^{1 / s}+\beta^{1 / s}\right) \quad \text { if } \quad \alpha \geqq 0 \quad \text { and } \quad \beta \geqq 0, \\
& \lambda n\left(\inf \beta_{i}\right)^{1 / s} \leqq\left(\sum_{1}^{n} \beta_{i}\right)^{1 / s} \quad \text { if } \beta_{i} \geqq 0 \quad \text { for each } i
\end{aligned}
$$

Since there is a basic sequence $\left\{e_{i}\right\}$ with characteristic not less than $\varepsilon$ and a sequence $\left\{a_{i}\right\}$ for which (1) is false, there also is a least positive integer $m$ for which

$$
\sup \frac{\left\|\sum_{1}^{m} \alpha_{i} e_{i}\right\|}{\left[\sum_{1}^{m}\left|a_{i}\right|^{s}\right]^{1 / s}}=M>\Phi
$$

where the sup is over all $m$-tuples of numbers $\left(a_{1}, \cdots, a_{m}\right)$. Since

$$
\frac{\left\|\sum_{1}^{m-1} a_{i} e_{i}+a_{m} e_{m}\right\|}{\left[\sum_{1}^{m-1}\left|a_{i}\right|^{s}+\left|a_{m}\right|^{s}\right]^{1 / s}} \leqq \frac{\left\|\sum_{1}^{m-1} a_{i} e_{i}\right\|}{\left[\sum_{1}^{m-1}\left|a_{i}\right|^{s}\right]^{1 / s}}+\frac{\left\|a_{m} e_{m}\right\|}{\left[\left|a_{m}\right|^{s}\right]^{1 / s}} \leqq \Phi+1,
$$

we have $\Phi<M \leqq \Phi+1$ and it follows from (2) that

$$
\left[\frac{M\left(1-\lambda^{2}\right)}{\lambda^{2} M-1}\right]^{s}<\frac{M\left(1-\lambda^{2}\right)}{\lambda^{2} M-1}<\frac{1}{n}\left(1-\theta^{1 / 4}\right) .
$$

Let $\left(\alpha_{1}, \cdots, \alpha_{m}\right)$ be an $m$-tuple such that $\left\|\sum_{1}^{m} \alpha_{i} e_{i}\right\|=1$ and

$$
\frac{1}{\left[\sum_{1}^{m}\left|\alpha_{i}\right|^{s}\right]^{1 / s}}=\frac{\left\|\sum_{1}^{m} \alpha_{i} e_{i}\right\|}{\left[\sum_{1}^{m}\left|\alpha_{i}\right|^{s}\right]^{1 / s}}>\lambda M .
$$

We shall show first that, for each $k$,

$$
\left|\alpha_{k}\right|^{s}<\frac{1}{n}\left(1-\theta^{1 / 4}\right) \sum_{1}^{m}\left|\alpha_{i}\right|^{s} .
$$

It follows from (3), (7) and (5) that, for each $k$,

$$
\left[\sum_{1}^{m}\left|\alpha_{i}\right|^{s}\right]^{1 / s} \geqq \lambda\left\{\left|\alpha_{k}\right|+\left[\sum_{i \neq k}\left|\alpha_{i}\right|^{s}\right]^{1 / s}\right\}
$$

and

$$
\lambda^{2} M<\frac{\left|\alpha_{k}\right|+\left\|\sum_{i \neq k} \alpha_{i} e_{i}\right\|}{\left|\alpha_{k}\right|+\left[\sum_{i \neq k}\left|\alpha_{i}\right|^{s}\right]^{1 / s}} \leqq \frac{\left|\alpha_{k}\right|+M\left[\sum_{i \neq k}\left|\alpha_{i}\right|^{s}\right]^{1 / s}}{\left|\alpha_{k}\right|+\left[\sum_{i \neq k}\left|\alpha_{i}\right|^{s}\right]^{1 / s}}
$$

Since $\lambda^{2} M-1>\lambda^{2} \Phi-1>0$, direct computation shows that (9) implies 


$$
\left|\alpha_{k}\right|:<\frac{M\left[\sum_{i \neq k}\left|\alpha_{i}\right|^{s}\right]^{1 / s}\left(1-\lambda^{2}\right)}{\lambda^{2} M-1} \leqq\left[\sum_{1}^{m}\left|\alpha_{i}\right|^{s}\right]^{1 / s} \frac{M\left(1-\lambda^{2}\right)}{\lambda^{2} M-1},
$$

which with (6) implies (8). Now that (8) has been established, we know there is a sequence of $n$ integers $\{m(1), \cdots, m(n)=m\}$ such that, for each $j$,

$$
\left|\left[\sum_{i=1}^{m(j)}\left|\alpha_{i}\right|^{s}-\frac{j}{n} \sum_{1}^{m}\left|\alpha_{i}\right|^{s}\right]\right|<\frac{1}{2 n}\left(1-\theta^{1 / 4}\right) \sum_{1}^{m}\left|\alpha_{i}\right|^{s} .
$$

Let us write

$$
\begin{aligned}
\sum_{1}^{m} \alpha_{i} e_{i} & =\sum_{1}^{m(1)} \alpha_{i} e_{i}+\sum_{m(1)+1}^{m(2)} \alpha_{i} e_{i}+\cdots+\sum_{m(n-1)+1}^{m} \alpha_{i} e_{i} \\
& =\sum_{1}^{n} u_{j},
\end{aligned}
$$

where $u_{j}=\sum_{m(j-1)+1}^{m(j)} \alpha_{i} e_{i}$ with $m(0)=0$. Then we have, for each $j$,

$$
\left|\left[\sum_{m(j-1)+1}^{m(j)}\left|\alpha_{i}\right|^{s}-\frac{1}{n} \sum_{1}^{m}\left|\alpha_{i}\right|^{s}\right]\right|<\frac{1}{n}\left(1-\theta^{1 / 4}\right) \sum_{1}^{m}\left|\alpha_{i}\right|^{s} .
$$

This implies that

$$
\frac{1}{n} \theta^{1 / 4} \sum_{1}^{m}\left|\alpha_{i}\right|^{s}<\sum_{m(j-1)+1}^{m(j)}\left|\alpha_{i}\right|^{s}<\frac{1}{n}\left(2-\theta^{1 / 4}\right) \sum_{1}^{m}\left|\alpha_{i}\right|^{s}<\frac{1}{n} \theta^{-1 / 4} \sum_{1}^{m}\left|\alpha_{i}\right|^{s}
$$

and

$$
\sum_{m(j-1)+1}^{m(j)}\left|\alpha_{i}\right|^{s}<\theta^{-1 / 2} \inf \left\{\sum_{m(k-1)+1}^{m(k)}\left|\alpha_{i}\right|^{s}: 1 \leqq k \leqq n\right\}
$$

for each $j$. It follows from (7), (5), (10), (4) and $\lambda^{2}>\theta^{1 / 2}$ that

$$
\begin{aligned}
\frac{1}{\left[\sum_{1}^{m}\left|\alpha_{i}\right|^{s^{1 / s}}\right]^{1 / s}}>\lambda M & \geqq \frac{\lambda\left\|u_{j}\right\|}{\left[\sum_{m(j-1)+1}^{m(j)}\left|\alpha_{i}\right|^{s}\right]^{1 / s}}>\frac{\left(\theta^{1 / 2}\right)^{1 / s} \lambda\left\|u_{j}\right\|}{\left[\inf _{k} \sum_{m(k-1)+1}^{m(k)}\left|\alpha_{i}\right|^{s}\right]^{1 / s}} \\
& >\frac{n\left(\theta^{1 / 2}\right)^{1 / s} \lambda^{2}\left\|u_{j}\right\|}{\left[\sum_{1}^{m}\left|\alpha_{i}\right|^{s}\right]^{1 / s}}>\frac{n \theta\left\|u_{j}\right\|}{\left[\sum_{1}^{m}\left|\alpha_{i}\right|^{s}\right]^{1 / s}},
\end{aligned}
$$

so that $\left\|u_{j}\right\|<1 /(n \theta)$. We are now prepared to show that $\left\{x_{1}, \cdots, x_{n}\right\}$ satisfies (ii) of Theorem 1 if $x_{j}=n \theta u_{j}$ for each $i, \alpha=1 / 2$ and $\beta=\varepsilon$. Note first that if $\Sigma \beta_{j}=1$ and $\beta_{j} \geqq 0$ for each $j$, then

$$
\begin{aligned}
\left\|\Sigma \beta_{j} x_{j}\right\| & \geqq\left\|\Sigma x_{j}\right\|-\left\|\Sigma\left(1-\beta_{j}\right) x_{j}\right\| \\
& \geqq n \theta\left\|\Sigma u_{j}\right\|-\Sigma\left(1-\beta_{j}\right) .
\end{aligned}
$$

Since $\left\|\Sigma u_{j}\right\|=\left\|\Sigma \alpha_{i} e_{i}\right\|=1$ and $\theta>1-1 /(2 n)$, we have 


$$
\left\|\Sigma_{\beta_{j} x_{j}}\right\| \geqq\left(n-\frac{1}{2}\right)-(n-1)=\frac{1}{2}=\alpha .
$$

Since the characteristic of the basic sequence $\left\{e_{i}\right\}$ is not less than $\varepsilon=\beta$, we also have

$$
\left\|\sum_{1}^{n} a_{i} x_{i}\right\| \geqq \beta\left\|\sum_{1}^{k} a_{i} x_{i}\right\| \quad \text { if } \quad k<n .
$$

The duality argument used by Gurariǐ and Gurariǐ [4] in a similar situation does not seem easily adaptible to give a proof of Theorem 3 that makes explicit use of Theorem 2. Therefore a direct proof of Theorem 3 will be given.

THEOREM 3. Let $B$ be a super-reflexive Banach space. If $\dot{\phi}$ and $\varepsilon$ are numbers for which $0<2 \phi<\varepsilon \leqq 1$, then there is a number $r$ for which $1<r<\infty$ and, if $\left\{e_{i}\right\}$ is any normalized basic sequence in $B$ with characteristic not less than $\varepsilon$, then

$$
\phi\left[\Sigma\left|a_{i}\right|^{r}\right]^{1 / r} \leqq\left\|\Sigma a_{i} e_{i}\right\|,
$$

for all numbers $\left\{a_{i}\right\}$ such that $\Sigma a_{i} e_{i}$ is convergent.

Proof. Suppose that $0<2 \phi<\varepsilon \leqq 1$. It will be shown that if no such number $r$ exists, then $B$ has property (iii) of Theorem 1 with $\alpha^{\prime}=2 \dot{\phi}^{2} / \varepsilon$ and $\beta^{\prime}>1 / \varepsilon$.

Let $n$ be an arbitrary positive integer greater than 1 . Let $\lambda$ be a positive number for which

$$
2 \phi<\lambda^{2} \varepsilon \text { and } \lambda<1 .
$$

Then choose $r>1$ and large enough that

$$
n^{1 / r}<\lambda^{-1}(1-\lambda)^{1 / r} \text {. }
$$

If $\beta_{i} \geqq 0$ for each $i$, then it follows from (12) that

$$
\left(\sum_{1}^{n} \beta_{i}\right)^{1 / r}<\lambda^{-1}\left(\sup \beta_{i}\right)^{1 / r}
$$

Since there is a basic sequence $\left\{e_{i}\right\}$ with characteristic not less than $\varepsilon$ and a sequence $\left\{a_{i}\right\}$ for which (11) is false, there also is an $m$ for which

$$
\inf \frac{\left\|\sum_{1}^{m} a_{i} e_{i}\right\|}{\left[\sum_{1}^{m}\left|a_{i}\right|^{r}\right]^{1 / r}}=M<\phi,
$$

where the inf is over all $m$-tuples of numbers $\left(a_{1}, \cdots, a_{m}\right)$. Let 
$\left(\alpha_{1}, \cdots, \alpha_{m}\right)$ be an $m$-tuple such that $\left\|\sum_{1}^{m} \alpha_{i} e_{i}\right\|=1$ and

$$
\frac{1}{\left[\sum_{1}^{m}\left|\alpha_{i}\right|^{r}\right]^{1 / r}}=\frac{\left\|\sum_{1}^{m} \alpha_{i} e_{i}\right\|}{\left[\sum_{1}^{m}\left|\alpha_{i}\right|^{r}\right]^{1 / r}}<M \lambda^{-1}
$$

As is true for all basic sequences with characteristic not less than $\varepsilon$, $\left\|\sum_{1}^{m} \alpha_{i} e_{i}\right\| \geqq(1 / 2) \varepsilon\left|\alpha_{k}\right|$ for each $k$. Thus it follows from (15) that

$$
\left|\alpha_{k}\right| \leqq \frac{2}{\varepsilon}\left\|\sum_{1}^{m} \alpha_{i} e_{i}\right\|<\frac{2 M}{\varepsilon \lambda}\left[\sum_{1}^{m}\left|\alpha_{i}\right|^{r}\right]^{1 / r} .
$$

Since $M<\phi$ and $2 \phi<\lambda^{2} \varepsilon$, it follows from (16) and (12) that

$$
\left|\alpha_{k}\right|^{r}<\lambda^{r} \sum_{1}^{m}\left|\alpha_{i}\right|^{r}<\frac{1}{n}(1-\lambda) \sum_{1}^{m}\left|\alpha_{i}\right|^{r} \text {. }
$$

Therefore, there is a sequence of $n$ integers $\{m(1), \cdots, m(n)=m\}$ such that, for each $j$,

$$
\left|\left[\sum_{i=1}^{m(j)}\left|\alpha_{i}\right|^{r}-\frac{j}{n} \sum_{1}^{m}\left|\alpha_{i}\right|^{r}\right]\right|<\frac{1}{2 n}(1-\lambda) \sum_{1}^{m}\left|\alpha_{i}\right|^{r} .
$$

Let us write

$$
\begin{aligned}
\sum_{1}^{m} \alpha_{i} e_{i} & =\sum_{1}^{m(1)} \alpha_{i} e_{i}+\sum_{m(1)+1}^{m(2)} \alpha_{i} e_{i}+\cdots+\sum_{m(n-1)+1}^{m} \alpha_{i} e_{i} \\
& =\sum_{1}^{n} u_{j},
\end{aligned}
$$

where $u_{j}=\sum_{m(j-1)+1}^{m(j)}$ with $m(0)=0$. Then we have, for each $j$,

$$
\left|\left[\sum_{m(j-1)+1}^{m(j)}\left|\alpha_{i}\right|^{r}-\frac{1}{n} \sum_{1}^{m}\left|\alpha_{i}\right|^{r}\right]\right|<\frac{1}{n}(1-\lambda) \sum_{1}^{m}\left|\alpha_{i}\right|^{r} .
$$

This implies that

$$
\frac{1}{n} \lambda \sum_{1}^{m}\left|\alpha_{i}\right|^{r}<\sum_{m(j-1)+1}^{m(j)}\left|\alpha_{i}\right|^{r}<\frac{1}{n}(2-\lambda) \sum_{1}^{m}\left|\alpha_{i}\right|^{r}<\frac{1}{n} \lambda^{-1} \sum_{1}^{m}\left|\alpha_{i}\right|^{r}
$$

and

$$
\sum_{m(j-1)+1}^{m(j)}\left|\alpha_{i}\right|^{r}>\lambda^{2} \sup \left\{\sum_{m(k-1)+1}^{m(k)}\left|\alpha_{i}\right|^{r}: 1 \leqq k \leqq n\right\} .
$$

It follows from (15), (14), (17), and (13) that, for each $j$, 


$$
\begin{aligned}
\frac{\lambda}{\left[\sum_{1}^{m}\left|\alpha_{i}\right|^{r}\right]^{1 / r}}<M \leqq \frac{\left\|u_{j}\right\|}{\left[\sum_{m(j-1)+1}^{m(j)}\left|\alpha_{i}\right|^{r}\right]^{1 / r}} & <\frac{\left\|u_{j}\right\|}{\lambda^{2 / r}\left[\sup _{k} \sum_{m(k-1)+1}^{m(k)}\left|\alpha_{i}\right|^{r}\right]^{1 / r}} \\
& <\frac{\left\|u_{j}\right\|}{\lambda^{3}\left[\sum_{1}^{m}\left|\alpha_{i}\right|^{r}\right]^{1 / r}},
\end{aligned}
$$

so that $\left\|u_{j}\right\|>\lambda^{4}$. Since $\left\{e_{i}\right\}$ is a basis with constant not less than $\varepsilon$ and $\lambda^{4}>4 \phi^{2} / \varepsilon^{2}$, this implies

$$
\left\|\sum_{1}^{n} a_{j} u_{j}\right\| \geqq \frac{1}{2} \varepsilon\left\|a_{k} u_{k}\right\| \geqq \frac{1}{2} \varepsilon \lambda^{4}\left|a_{k}\right| \geqq \frac{2 \phi^{2}}{\varepsilon}\left|a_{k}\right|=\alpha^{\prime}\left|a_{k}\right|
$$

for all numbers $\left\{a_{i}\right\}$ and each $k \leqq n$. Now we can use

$$
1=\left\|\sum_{1}^{m} \alpha_{i} e_{i}\right\|=\left\|\sum_{1}^{n} u_{j}\right\| \geqq \varepsilon\left\|\sum_{1}^{k} u_{j}\right\|
$$

to obtain $\left\|\sum_{1}^{k} u_{j}\right\| \leqq 1 / \varepsilon<\beta^{\prime}$.

THEOREM 4. Let $B$ be a Banach space that is super-reflexive. If $0<2 \phi<\varepsilon \leqq 1<\Phi$, then there are numbers $r$ and $s$ for which $1<r<\infty, 1<s<\infty$ and, if $\left\{e_{i}\right\}$ is any normalized basic sequence in $B$ with characteristic not less than $\varepsilon$, then

$$
\phi\left[\sum\left|a_{i}\right|^{r}\right]^{1 / r} \leqq\left\|\sum a_{i} e_{i}\right\| \leqq \Phi\left[\sum\left|a_{i}\right|^{s}\right]^{1 / s}
$$

for all numbers $\left\{a_{i}\right\}$ such that $\sum a_{i} e_{i}$ is convergent.

An examination of the proofs of Theorems 2 and 3 will show that essentially the same arguments can be used for nonseparable Banach spaces and unconditional basic subsets. Therefore:

THEOREM 5. Let $B$ be Banach space that is super-reflexive. If $0<2 \phi<\varepsilon \leqq 1<\Phi$, then there numbers $r$ and $s$ for which $1<r<\infty$, $1<s<\infty$ and, if $\left\{e_{\alpha}\right\}$ is any normalized unconditional basic subset of $B$ with characteristic not less than $\varepsilon$, then

$$
\phi\left[\sum\left|a_{\alpha}\right|^{r}\right]^{1 / r} \leqq\left\|\sum a_{\alpha} e_{\alpha}\right\| \leqq \Phi\left[\sum\left|a_{\alpha}\right|^{s}\right]^{1 / s},
$$

for all numbers $\left\{a_{\alpha}\right\}$ such that $\sum a_{\alpha} e_{\alpha}$ is convergent.

It is stated in [4] that it is not known whether $B$ is isomorphic to a space that is uniformly convex and uniformly smooth if, for each normalized basic sequence $\left\{e_{i}\right\}$ in $B$, there are positive numbers $\phi, \Phi$, $r$ and $s$ such that $1<r<\infty, 1<s<\infty$, and

$$
\phi\left[\sum\left|a_{i}\right|^{r}\right]^{1 / r} \leqq\left\|\sum a_{i} e_{i}\right\| \leqq \Phi\left[\sum\left|a_{i}\right|^{s}\right]^{1 / s} .
$$


This conjecture would be strongly suggested by the next theorem, if it should be true that every super-reflexive space is isomorphic to a uniformly convex space. It would then also follow that uniform convexity, uniform smoothness, and super-reflexivity are equivalent within isomorphism and that the existence of numbers $\phi, \Phi, r$ and $s$ that satisfy the inequalities of Theorem 4 could be deduced from the results of Gurariǐ and Gurariǐ [4].

THEOREM 6. Each of the following is a necessary and sufficient condition for a Banach space $B$ to be super-reflexive.

(a) If $0<2 \phi<\varepsilon \leqq 1<\Phi$, then there are numbers $r$ and $s$ for which $1<r<\infty, 1<s<\infty$, and, if $\left\{e_{i}\right\}$ is any normalized basic sequence in $B$ with characteristic not less than $\varepsilon$, then

$$
\phi\left[\sum\left|a_{i}\right|^{r}\right]^{1 / r} \leqq\left\|\sum a_{i} e_{i}\right\| \leqq \Phi\left[\sum\left|a_{i}\right|^{s}\right]^{1 / s},
$$

for all number $\left\{a_{i}\right\}$ such that $\sum a_{i} e_{i}$ is convergent.

(b) If $0<\varepsilon \leqq 1<\Phi$, then there is a number $s$ for which $1<s<\infty$, and, if $\left\{e_{i}\right\}$ is any normalized basic sequence in $B$ with characteristic not less than $\varepsilon$, then

$$
\left\|\sum a_{i} e_{i}\right\| \leqq \Phi\left[\sum\left|a_{i}\right|^{s}\right]^{1 / s},
$$

for all numbers $\left\{a_{i}\right\}$ such that $\sum a_{i} e_{i}$ is convergent.

(c) There exist numbers $\varepsilon$, $\Phi$ and $s$ such that $0<\varepsilon<1 / 2$, $1<s<\infty$, and, if $\left\{e_{i}\right\}$ is any normalized basic sequence in $B$ with characteristic not less than $\varepsilon$, then

$$
\left\|\sum a_{i} e_{i}\right\| \leqq \Phi\left[\sum\left|a_{i}\right|^{s}\right]^{1 / s},
$$

for all numbers $\left\{a_{i}\right\}$ such that $\sum a_{i} e_{i}$ is convergent.

Proof. It follows from Theorem 4 that super-reflexivity implies (a). The implications (a) $\Rightarrow(\mathrm{b}) \Rightarrow$ (c) are purely formal. To prove that (c) implies that $B$ is super-reflexive, let us suppose that $B$ is not super-reflexive and that there exist numbers $\varepsilon, \Phi$ and $s$ as described in (c). Choose a positive integer $n$ such that

$$
n^{1-1 / s}>\frac{\Phi}{\varepsilon} .
$$

It is known that in (ii) of Theorem 1 we can require that $\varepsilon<\alpha=\beta$ (see the definition of $P_{3}$ and Theorem 6, both in [8]). Therefore there is a subset $\left\{x_{1}, \cdots, x_{n}\right\}$ of the unit ball for which $\|x\|>\varepsilon$ if $x \in \operatorname{conv}\left\{x_{1}, \cdots, x_{n}\right\}$ and $\left\|\sum_{1}^{n} a_{i} x_{i}\right\| \geqq \beta\left\|\sum_{1}^{k} a_{i} x_{i}\right\|$ for all $k<n$ and all numbers $\left\{a_{1}, \cdots, a_{n}\right\}$. Then $\left\{x_{i}\right\}$ can be the initial segment of a basic sequence with characteristic not less than $\varepsilon$ and it follows from 
(18) that

$$
\left\|\sum_{1}^{n} x_{i}\right\| \leqq \Phi n^{1 / s}
$$

Since $\left\|\sum_{1}^{n} x_{i}\right\|>n \varepsilon$, we have a contradiction of (19).

Recall that, relative to a basis $\left\{e_{i}\right\}$, a block basic sequence is a sequence $\left\{e_{i}^{\prime}\right\}$ for which there is an increasing sequence of positive integers $\{n(i)\}$ such that $n(1)=1$ and

$$
e_{k}^{\prime}=\sum_{n(k)}^{n(k+1)-1} a_{i} e_{i}, \quad k=1,2, \cdots
$$

THEOREM 7. $A$ Banach space $B$ is reflexive if $B$ has a basis $\left\{e_{i}\right\}$ and, for each normalized block basic sequence $\left\{e_{i}^{\prime}\right\}$ of $\left\{e_{i}\right\}$, there are positive numbers $\phi, \Phi, r$ and $s$ such that $1<r<\infty, 1<s<\infty$, and

$$
\phi\left[\sum\left|a_{i}\right|^{r}\right]^{1 / r} \leqq\left\|\sum a_{i} e_{i}^{\prime}\right\| \leqq \Phi\left[\sum\left|a_{i}\right|^{s}\right]^{1 / s},
$$

for all numbers $\left\{a_{i}\right\}$ such that $\sum \alpha_{i} e_{i}^{\prime}$ is convergent.

Proof. If $\left\{e_{i}\right\}$ is not boundedly complete, there is a sequence $\left\{u_{i}\right\}$ and a positive number $\Delta$ such that $\left\|\sum_{1}^{n} u_{i}\right\|$ is bounded, $\left\|u_{i}\right\|>\Delta$, and

$$
u_{i}=\sum_{n(k)}^{n(k+1)-1} a_{i} e_{i}, \quad k=1,2, \cdots,
$$

where $\{n(i)\}$ is an increasing sequence of positive integers. Let $e_{i}^{\prime}=$ $u_{i} /\left\|u_{i}\right\|$. Then $\left\|\left(\sum_{1}^{n}\left\|u_{i}\right\| e_{i}^{\prime}\right)\right\|$ is bounded, but there do not exist $\phi>0$ and $1<r<\infty$ such that $\phi \sum_{1}^{n}\left\|u_{i}\right\|^{r}>\phi n \Delta^{n}$ is bounded. If $\left\{e_{i}\right\}$ is not shrinking, there is a normalized block basic sequence $\left\{e_{i}^{\prime \prime}\right\}$ such that $\left\|\sum_{1}^{n} e_{i}^{\prime \prime}\right\|>(1 / 2) n$ for all $n$. But there do not exist $\Phi$ and $s>1$ such that $\Phi n^{1 / s}>(1 / 2) n$ for all $n$. Thus $\left\{e_{i}\right\}$ is boundedly complete and shrinking, which implies $B$ is reflexive [2, Theorem 3, p. 71].

The next example shows that Theorem 7 can not be strengthened by assuming that (20) is satisfied only for a basis for $B$, even if $\phi=$ $\Phi=1, s=2$, and $r$ is close to 2 .

Example. Choose $r>2$ and positive integers $\left\{n_{i}\right\}$ so that $\left(n_{i}\right)^{(1 / 2) r-1}>2^{i}$ for each $i$. For each $k$, let $v^{k}$ be the sequence that has zeros except for $k$ initial blocks, the $i$ th block having $n_{i}$ components each equal to $\left(n_{i}\right)^{-1 / 2}$. Let $B$ be the completion of the space of all sequences of real numbers with only a finite number of nonzero components and, if $x=\left\{x_{i}\right\}$,

$$
\|x\|=\inf \left\{\left(\sum u_{i}^{2}\right)^{1 / 2}+\sum\left|a_{k}\right|: x=u+\sum a_{k} v^{k}\right\} .
$$


If $\left\|\left\{y_{i}\right\}\right\|_{r}$ denotes $\left[\sum\left|y_{i}\right|^{r}\right]^{1 / r}$, then $\left(\sum u_{i}^{2}\right)^{1 / 2} \geqq\|u\|_{r}$ and

$$
\left\|v^{k}\right\|_{r}=\left[n_{1}^{1-1 / 2 r}+n_{2}^{1-1 / 2 r} \cdots+\left(n_{p(k)}\right)^{1-1 / 2 r}\right]^{1 / r}<1 \text {. }
$$

Therefore

$$
\|x\| \geqq\|u\|_{r}+\sum\left\|a_{k} v^{k}\right\|_{r} \geqq\|x\|_{r} \text {. }
$$

It follows directly from (21) that $\|x\| \leqq\left(\sum x_{i}^{2}\right)^{1 / 2}$. It follows from the facts that $\left\|v^{k}\right\| \leqq 1$ for all $k$ and that a sequence has norm 1 if it contains all zeros except for one block of $n_{i}$ terms each equal to $n_{i}^{-1 / 2}$, that the natural basis for $B$ is not boundedly complete and $B$ is not reflexive.

It was shown by N. I. Gurariǐ [5, Theorem 7] that, for any $r$ and $s$ with $1<r<\infty$ and $1<s<\infty$, there is a basis $\left\{e_{i}\right\}$ for Hilbert space such that for any positive numbers $\phi$ and $\Phi$ there are finite sequences $\left\{a_{i}\right\}$ and $\left\{b_{i}\right\}$ for which

$$
\phi\left[\sum\left|a_{i}\right|^{r}\right]^{1 / r}>\left\|\sum a_{i} e_{i}\right\| \text { and }\left\|\sum b_{i} e_{i}\right\|>\Phi\left[\left.\sum a_{i}\right|^{s}\right]^{1 / s} \text {. }
$$

Thus for Hilbert space there can be neither an upper bound $\rho<\infty$ for $r$ nor a lower bound $\sigma<1$ for $s$ in Theorems 2-5, even if $\phi$ and $\Phi$ are allowed to depend on the basic sequence.

\section{REFERENCES}

1. S. Banach, Théorie des Opérations Linéaires, Warsaw, 1932.

2. M. M. Day, Normed Linear Spaces, New York, 1962.

3. M. M. Grinblum, Certain théorèms sur la base dans un espace de type $(B)$, Dokl. Akad. Nauk SSSR, 31 (1941), 428-432.

4. V. I. Gurariǐ and N. I. Gurariǐ, On bases in uniformly convex and uniformly smooth Banach spaces, Izv. Akad. Nauk SSSR Ser. Mat., 35 (1971), 210-215.

5. N. I. Gurariǐ, On sequential coefficients of expansions with respect to bases in Hilbert and Banach spaces, Izv. Akad. Nauk SSSR Ser. Mat., 35 (1971), 216-223.

6. R. C. James, Uniformly non-square Banach spaces, Ann. of Math., 80 (1964), 542550 .

7. - Weak compactness and separation, Israel J. Math., 2 (1964), 101-119.

8. - Some self-dual properties of normed linear spaces, Symposium on Infinite Dimensional Topology, Annals of Mathematics Studies, 69 (1972).

Received July 20, 1971. This work was supported in part by NSF Grant GP 20838. 



\section{PACIFIC JOURNAL OF MATHEMATICS}

\section{EDITORS}

\author{
H. SAMELSON \\ Stanford University \\ Stanford, California 94305

\section{R. HoвBY} \\ University of Washington \\ Seattle, Washington 98105
}

\section{J. DugundJI}

Department of Mathematics University of Southern California Los Angeles, California 90007

\author{
RichaRd ARENS \\ University of California \\ Los Angeles, California 90024
}

\section{ASSOCIATE EDITORS}
E. F. BECKENBACH
B. H. NEUMANN
F. WOLF
K. YoshidA

\section{SUPPORTING INSTITUTIONS}

\author{
UNIVERSITY OF BRITISH COLUMBIA \\ CALIFORNIA INSTITUTE OF TECHNOLOGY \\ UNIVERSITY OF CALIFORNIA \\ MONTANA STATE UNIVERSITY \\ UNIVERSITY OF NEVADA \\ NEW MEXICO STATE UNIVERSITY \\ OREGON STATE UNIVERSITY \\ UNIVERSITY OF OREGON \\ OSAKA UNIVERSITY
}

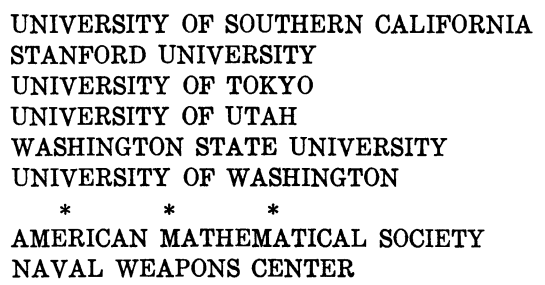

The Supporting Institutions listed above contribute to the cost of publication of this Journal, but they are not owners or publishers and have no responsibility for its content or policies.

Mathematical papers intended for publication in the Pacific Journal of Mathematics should be in typed form or offset-reproduced, (not dittoed), double spaced with large margins. Underline Greek letters in red, German in green, and script in blue. The first paragraph or two must be capable of being used separately as a synopsis of the entire paper. The editorial "we" must not be used in the synopsis, and items of the bibliography should not be cited there unless absolutely necessary, in which case they must be identified by author and Journal, rather than by item number. Manuscripts, in dup icate if possible, may be sent to any one of the four editors. Please classify according to the scheme of Math. Rev. Index to Vol. 39. All other communications to the editors should be addressed to the managing editor, Richard Arens, University of California, Los Angeles, California, 90024.

50 reprints are provided free for each article; additional copies may be obtained at cost in multiples of 50 .

The Pacific Journal of Mathematics is published monthly. Effective with Volume 16 the price per volume (3 numbers) is $\$ 8.00$; single issues, $\$ 3.00$. Special price for current issues to individual faculty members of supporting institutions and to individual members of the American Mathematical Society: $\$ 4.00$ per volume; single issues $\$ 1.50$. Back numbers are available.

Subscriptions, orders for back numbers, and changes of address should be sent to Pacific Journal of Mathematics, 103 Highland Boulevard, Berkeley, California, 94708.

PUBLISHED BY PACIFIC JOURNAL OF MATHEMATICS, A NON-PROFIT CORPORATION

Printed at Kokusai Bunken Insatsusha (International Academic Printing Co., Ltd.), 270, 3-chome Totsuka-cho, Shinjuku-ku, Tokyo 160, Japan. 


\section{Pacific Journal of Mathematics}

\section{Vol. 41, No. 2 December, 1972}

Tom M. (Mike) Apostol, Arithmetical properties of generalized Ramanujan sums .......................................... 281

David Lee Armacost and William Louis Armacost, On p-thetic groups ........ 295

Janet E. Mills, Regular semigroups which are extensions of groups .......... 303

Gregory Frank Bachelis, Homomorphisms of Banach algebras with minimal ideals ................................................ 307

John Allen Beachy, A generalization of injectivity .................. 313

David Geoffrey Cantor, On arithmetic properties of the Taylor series of rational functions. II.........................................

Václáv Chvátal and Frank Harary, Generalized Ramsey theory for graphs. III.

Small off-diagonal numbers .................................. 335

Frank Rimi DeMeyer, Irreducible characters and solvability of finite groups . . . . 347

Robert P. Dickinson, On right zero unions of commutative semigroups........ 355

John Dustin Donald, Non-openness and non-equidimensionality in algebraic

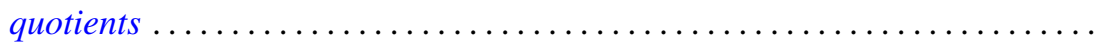

John D. Donaldson and Qazi Ibadur Rahman, Inequalities for polynomials with a prescribed zero ........................................ 375

Robert E. Hall, The translational hull of an $N$-semigroup ................ 379

John P. Holmes, Differentiable power-associative groupoids.............. 391

Steven Kenyon Ingram, Continuous dependence on parameters and boundary data for nonlinear two-point boundary value problems .

Robert Clarke James, Super-reflexive spaces with bases ..........

Gary Douglas Jones, The embedding of homeomorphisms of the plane in

continuous flows...............................

Mary Joel Jordan, Period $H$-semigroups and $t$-semisimple periodic

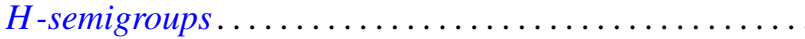

Ronald Allen Knight, Dynamical systems of characteristic 0

Kwangil Koh, On a representation of a strongly harmonic ring by sheaves...

Hui-Hsiung Kuo, Stochastic integrals in abstract Wiener space. ..

Thomas Graham McLaughlin, Supersimple sets and the problem of extending a

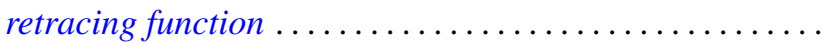

William Nathan, Open mappings on 2-manifolds .

M. J. O'Malley, Isomorphic power series rings

Sean B. O'Reilly, Completely adequate neighborhood systems and metrization

Qazi Ibadur Rahman, On the zeros of a polynomial and its derivative...

Russell Daniel Rupp, Jr., The Weierstrass excess function ..

Hugo Teufel, A note on second order differential inequalities and functional

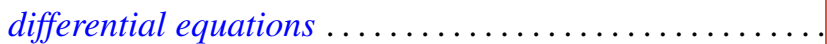

M. J. Wicks, A general solution of binary homogeneous equations over free 